DOI: https://doi.org/10.47405/mjssh.v5i10.492

\begin{tabular}{|c|c|}
\hline पy. & Malaysian Journal of Social Sciences and Humanities (MJSSH) \\
\hline Malaysian Journal of & Volume 5, Issue 10, October 2020 \\
\hline $\begin{array}{l}\text { (Muanantits } \\
\text { (MJ-SSH) }\end{array}$ & e-ISSN : 2504-8562 \\
\hline & $\begin{array}{l}\text { Journal home page: } \\
\text { www.msocialsciences.com }\end{array}$ \\
\hline
\end{tabular}

\title{
Perubahan Sistem Nilai dalam Sistem Bombon yang Diamalkan oleh Masyarakat Kadazandusun di Kiulu, Tuaran, Sabah
}

\author{
Jacinta Tangil ${ }^{1}$, Asmiaty Amat ${ }^{1}$ \\ ${ }^{1}$ Universiti Malaysia Sabah (UMS)
}

Correspondence: Jacinta Tangil (jessukm@yahoo.com)

\begin{abstract}
Abstrak
Tulisan ini membincangkan perubahan sistem nilai dalam amalan sistem bombon yang menjadi tradisi masyarakat Kadazandusun. Sistem bombon adalah satu kaedah pemuliharaan ikan air tawar yang dilaksanakan sejak zaman nenek moyang mereka. Melalui amalan sistem bombon, masyarakat Kadazandusun dapat melestarikan alam sekitar seterusnya dapat memastikan mereka mendapat sumber ikan secara berterusan. Tradisi bombon bertititik tolak daripada kepercayaan tradisional masyarakat Kadazandusun. Sistem bombon memperlihatkan kearifan tempatan, nilai, kelakuan serta sikap masyarakat Kadazandusun terhadap alam sekitar dan hubungan sesama manusia. Kajian ini menggunakan kaedah kajian lapangan berupa pemerhatian ikut serta dan temu bual secara mendalam di beberapa kampung di kampung Poturidung, Kampung Malangang dan Kampung Lokub, daerah Kiulu Tuaran, Sabah. Kajian mendapati bahawa manfaat pelaksanaan sistem bombon yang paling penting adalah sebagai agen penyatuan seluruh komuniti pengamal. Sebagai satu aktiviti yang dikaitkan dengan kepercayaan tradisional masyarakat tersebut, sistem bombon tidak dapat dipisahkan daripada hukum adat. Jika dahulu aktiviti budaya ini disaluti dengan sistem kepercayaan tradisional, namun pada hari ini, sistem bombon memperlihatkan perubahan sistem nilai melalui pelaksanaannya. Tradisi bombon diteruskan sehingga hari ini dengan dengan nilai yang sesuai dengan kehidupan pada hari ini. Amalan sistem bombon telah berjaya membuka sisi lain dalam kehidupan masyarakat Kadazandusun. Kini, sistem bombon bukan sahaja boleh dibanggakan sebagai warisan budaya masyarakat Kadazandusun malah sebagai salah satu warisan kebangsaan.
\end{abstract}

Kata kunci: kepercayaan tradisional, hukum adat, kearifan tempatan, bombon, Kadazandusun

\section{Changes in the Value System in the Bombon System Practiced by the Kadazandusun Community in Kiulu, Tuaran, Sabah}

\begin{abstract}
This article discusses the changes in the value system in the practice of the bombon system which has become a tradition of the Kadazandusun community. The bombon system is a method of conservation of freshwater fish implemented since the time of their ancestors. Through the practice of the bombon system, the Kadazandusun community can preserve the environment and in turn ensure that they have a continuous source of fish. The bombon tradition is based on the traditional beliefs of the Kadazandusun people. The bombon system shows the local wisdom, values, behavior and attitude of the Kadazandusun community towards the environment and human relations. This study uses field study methods in the form of participatory observations and in-depth interviews in several villages in the villages of Poturidung, Kampung Malangang and Kampung Lokub, Kiulu Tuaran district, Sabah. The
\end{abstract}


study found that the most important benefit of the implementation of the bombon system is as a unifying agent of the entire community of practitioners. As an activity associated with the traditional beliefs of the community, the bombon system is inseparable from customary law. If in the past these cultural activities were coated with traditional belief systems, but today, the bombon system shows changes in the value system through its implementation. The bombon tradition continues to this day with values that are relevant to life today. The practice of the bombon system has successfully opened the other side in the life of the Kadazandusun community. Today, the bombon system can not only be proud of as the cultural heritage of the Kadazandusun community but also as one of the national heritage.

Keywords: traditional beliefs, customary law, local wisdom, bombon, Kadazandusun

\section{Pengenalan}

Masyarakat Kadazandusun merupakan penduduk asli terbesar di Sabah, iaitu satu pertiga daripada keseluruhan jumlah penduduk. Masyarakat Kadazandusun secara tradisi adalah masyarakat yang mengamalkan aktiviti pertanian, terutamanya penanaman padi sawah dan padi bukit (Luping, 2009:94) dan mereka menganut kepercayaan berbentuk animisme. Mereka juga menjalankan aktiviti berburu serta menangkap ikan sungai. Masyarakat tersebut kaya dengan adat dan budaya tradisi yang diwarisi daripada nenek moyang mereka yang bertitik tolak daripada kepercayaan tradisional mereka. Evans (1923) menerangkan bahawa masyarakat Kadazandusun percaya bahawa setiap unsur alam mempunyai semangat ghaib atau penunggu. Oleh itu mereka perlu mengadakan pelbagai persembahan atau ritual agar dapat mewujudkan hubungan yang baik dengan semangat dan penunggu tersebut.

\section{Permasalahan dan Objektif Kajian}

Kepercayaan terhadap semangat atau kuasa luar biasa yang terdapat pada benda atau unsur alam semula jadi menyebabkan masyarakat Kadazandusun sentiasa berusaha untuk menjaga hubungan yang baik dengan alam. Mereka percaya bahawa konflik yang wujud antara manusia dengan alam semula jadi boleh menyebabkan semangat atau penunggu yang mendiami sesuatu kawasan atau benda boleh mengakibatkan penyakit, kecelakaan atau malapetaka kepada manusia. Kepercayaan tersebut telah mengikat masyarakat Kadazandusun untuk saling bekerjasama demi mengekalkan hubungan yang baik dengan alam semula jadi (Williams 1965: 90). Setiap perlakuan yang dikaitkan dengan kepercayaan tradisional masyarakat tersebut akhirnya membentuk amalan yang akhirnya menjadi adat dan kepercayaan mereka. Pegangan terhadap adat penting dalam setiap perlakuan dan perjalanan kehidupan masyarakat Kadazandusun. Maka itu, peraturan-peraturan tertentu diwujudkan sehingga akhirnya menjadi hukum adat bagi masyarakat Kadazandusun. Kepatuhan kepada adat itu sendiri membentuk nilai dan norma yang berjaya menyatukan segala tindakan mereka.

Kebanyakan aktiviti tradisi yang dilakukan oleh masyarakat perlu dilakukan dengan berhati-hati bagi mengelakkan kemarahan semangat ghaib dan penunggu. Sistem bombon merupakan antara amalan yang dikaitkan dengan kepercayaan tradisional masyarakat Kadazandusun. Oleh itu amalan tersebut turut dipengaruhi oleh hukum adat. Sistem bombon adalah satu sistem pengurusan sungai secara tradisional dengan menggunakan pendekatan secara semula jadi, iaitu dengan mengehadkan penggunaan sumber di satu kawasan untuk tujuan pemuliharaan. Amalan sistem bombon dapat memastikan penduduk mendapat sumber makanan dari sungai secara berterusan. Amalan bombon dilingkari dengan kepercayaan tradisional masyarakat Kadazandusun. Melalui amalan ini, dapat diserlahkan nilai sosial serta idea kehidupan masyarakat Kadazandusun. Walau bagaimanapun, sistem nilai yang telah disepakati masyarakat sejak dahulu dianggap berubah apabila sistem bombon yang diamalkan turut mengubah perspektif dan persepsi masyarakat pengamalnya. Bombon pada masa kini dilihat lebih menjurus kepada kesatuan dan perpaduan komuniti pengamal selain bersifat komersial dan juga berbentuk kesihatan dengan mewujudkan spa-ikan kepada para pengunjung. 
Oleh hal yang demikian, kertas kerja ini bertujuan membincangan perubahan sistem nilai yang mewarnai amalan sistem bombon oleh masyarakat Kadazandusun di Kiulu, Tuaran, Sabah. Amalan tersebut yang diwarisi daripada nenek moyang mereka pada asalnya dikaitkan dengan sistem kepercayaan tradisional mereka tetapi dianggap telah mengalami perubahan nilai seiring dengan arus kemodenan namun masih tetap menyerlahkan keunggulan identiti masyarakat tersebut.

\section{Kajian Lepas}

Terdapat beberapa orang sarjana yang menulis tentang sistem bombon seperti Wong et al (2009), Foo (2011), Er et al (2012) dan Foo dan Harifah Mohd. Noor (2012). Secara umumnya, kebanyakan tulisan mereka membincangkan kaedah pelaksanaan sistem bombon dalam masyarakat Kadazandusun. Mereka juga turut mengaitkan pelaksanaan sistem bombon dengan ekonomi komuniti setempat. Sistem bombon pada hari ini memberi manfaat besar kepada komuniti pengamal bombon dari segi ekonomi kerana diketengahkan sebagai satu produk pelancongan. Komuniti pengamal bombon mendapat pulangan ekonomi melalui pembukaan pusat pelancongan berasaskan alam. Selain itu sistem bombon juga dikaitkan dengan pelestarian alam dan peningkatan hasil ikan air tawar. Tulisan mereka juga turut membincangkan amalan bombon sebagai amalan yang diwarisi sejak zaman berzaman dan mempunyai konotasi dari segi adat. Hukuman pelanggaran peraturan yang ditetapkan dalam sistem bombon akan dikenakan berdasarkan adat masyarakat Kadazandusun.

Tongkul (2007), Minah (2013) dan Kulip (2016) turut membincangkan kaedah pelaksanaan sistem bombon. Sistem bombon turut dikaitkan dengan amalan kepercayaan tradisional nenek moyang masyarakat Kadazandusun. Manakala Adlina et al (2013) membincangkan sistem bombon sebagai salah satu kearifan tempatan masyarakat Kadazandusun dalam menjaga alam sekitar untuk tujuan pelestarian terutamanya sumber ikan. Seterusnya penelitian yang ditulis oleh Foo (2019) menyatakan bahawa sistem bombon merupakan amalan tradisional masyarakat Kadazandusun ditambah baik oleh Jabatan Perikanan Sabah untuk membentuk satu sistem yang bersifat lebih dinamik dan universal. Menurut kajian beliau, dengan kerjasama tersebut, warisan budaya masyakarakat dapat dipulihara melalui sistem bombon.

\section{Metod Kajian}

Kajian ini menggunakan kaedah pemerhatian ikut serta (participant observation) dan temu bual secara formal dan tidak formal. Kajian berkaitan sistem bombon difokuskan kepada kumpulan masyarakat Kadazandusun di beberapa buah kampung di Kiulu, Tuaran, Sabah iaitu Kampung Poturidung, Kampung Malangang dan Kampung Lokub. Hampir keseluruhan penduduk kampung tersebut merupakan masyarakat Kadazandusun dan masih mengamalkan adat tradisi yang dipraktikkan melalui sistem bombon. Kawasan Kiulu terletak dalam kawasan pentadbiran Daerah Tuaran dan mempunyai keluasan 537 kilometer persegi di Pantai Barat Negeri Sabah. Kiulu terletak lebih kurang 60 kilometer dari pusat Bandaraya Kota Kinabalu, iaitu ibu negeri Sabah. Kedudukan Kiulu di bawah kaki Banjaran Crocker dan bersempadan dengan daerah Penampang, Tambunan, Nabalu dan tanah tinggi Ranau telah mempengaruhi bentuk muka bumi Kiulu. Hampir 70 peratus keluasan Kiulu diliputi oleh bentuk muka bumi yang berbukit bukau.

Kajian ini juga menggunakan kaedah temu bual secara mendalam (in-depth interview). Melalui kaedah ini, semua informan yang ditemu bual dapat memberikan maklumat yang diperlukan untuk kajian ini. Informan-informan yang dipilih adalah berdasarkan pengalaman dan penglibatan mereka dalam mengendalikan hukum adat dan amalan budaya masyarakat Kadazandusun khususnya dalam pelaksanaan sistem bombon. Untuk memastikan maklumat yang diperoleh adalah sahih dan bermanfaat, kebanyakan informan yang ditemu bual adalah berumur 50 tahun ke atas, serta mempunyai kedudukan yang penting dalam masyarakat. Antara informan yang ditemu bual adalah Ketua Kampung, bekas Ketua Daerah, bekas pegawai kerajaan, bekas Ketua Kampung, dan 
budayawan yang kebanyakannya pernah dan masih aktif terlibat secara langsung dengan amalan aktiviti budaya yang dikaji.

\section{Sistem Bombon}

Sistem bombon merupakan kearifan tempatan masyarakat Kadazandusun dalam usaha pemuliharaan ikan sungai secara semula jadi untuk memastikan komuniti pengamal bombon menikmati sumber ikan secara berterusan dan berkekalan. Bombon dalam bahasa Kadazandusun adalah bermaksud "jangan" atau perbuatan yang "dilarang atau ditegah dengan adat"1. Melalui kaedah bombon, sebahagian daripada kawasan sungai terutama di sekitar kawasan lubuk dalam akan dikenakan bombon atau sekatan dan larangan menangkap ikan di kawasan tersebut dalam satu tempoh masa tertentu. Kawasan sungai yang lain masih terbuka untuk tujuan riadah dan aktiviti menangkap ikan tetapi hanya penggunaan alat yang tidak memudaratkan ikan dan persekitaran. Penggunaan racun kimia dan tuba adalah dilarang sama sekali. Tujuan bombon diadakan adalah untuk membantu pemuliharaan ikan. Melalui kaedah bombon, ikan dapat membiak dan bertambah dalam satu tempoh masa tertentu. Amalan sistem bombon juga dapat memberi masa kepada ikan-ikan untuk mencapai tahap matang sebelum dituai. Dalam tempoh masa tersebut, anggota komuniti dilarang sama sekali untuk menangkap ikan di kawasan yang telah dikenakan bombon. Kawasan yang dikenakan bombon juga menjadi kawasan larangan daripada sebarang aktiviti sosial kecuali untuk tujuan pembersihan yang dilakukan secara bergotong royong oleh komuniti pengamal bombon. Kawasan bombon dijaga daripada sebarang bentuk pencemaran termasuk pengambilan batuan dan pasir dari kawasan tersebut juga tidak dibenarkan.

Biasanya, ikan-ikan di kawasan bombon akan dituai dalam masa antara setahun hingga tiga tahun sekali, bergantung kepada persetujuan bersama semua anggota komuniti pengamal bombon. Pemilihan tarikh dan masa yang sesuai untuk menuai ikan hasil bombon disepakati bersama dengan mengambil kira situasi dan keadaan sosial pada masa itu dan faktor cuaca. Hari menuai ikan atau buka bombon dalam bahasa Kadazandusun dikenali sebagai maganu bombon. Pemilihan hari untuk maganu bombon biasanya mengambil kira keadaan cuaca dan seboleh-bolehnya dilakukan pada hari cuti umum agar semua anggota komuniti pengamal bombon dapat meluangkan masa bersama-sama dalam aktiviti menuai ikan. Keadaan cuaca yang panas dan kering pada musim kemarau menjadi pilihan untuk menetapkan hari maganu bombon. Cuaca panas yang panjang mengakibatkan air sungai menjadi cetek. Air sungai yang cetek memudahkan proses menangkap ikan dilakukan. Cuaca yang panas juga membolehkan penduduk mengambil kesempatan untuk beriadah beramai-ramai di sungai sambil menikmati ikan-ikan yang dituai pada hari tersebut. Selain hidangan berasaskan ikan, makanan tradisional lain turut disediakan oleh anggota komuniti. Hari maganu bombon dianggap seperti satu pesta kecil atau hari keluarga oleh anggota komuniti.

Hanya peralatan tradisional menangkap ikan dibenarkan untuk digunakan pada hari maganu bombon. Antara peralatan yang digunakan adalah pancing, pukat (rambat atau jala), jaring, bubu, siyud dan pana' ikan manakala semua bentuk tuba tumbuhan, racun atau bahan kimia dan bom ikan adalah diharamkan di kawasan bombon kerana boleh merosakkan dan mencemarkan kawasan sungai serta boleh mengakibatkan kepupusan ikan berlaku. Semua ikan yang ditangkap pada hari maganu bombon akan dibahagikan sama rata kepada semua penduduk, namun terdapat pembahagian khusus untuk anggota komuniti yang bertugas sebagai penyelam lubuk. Melalui amalan sistem bombon, semua anggota komuniti pengamal bombon akan mendapat bahagian ikan hasil tuaian daripada kawasan sungai yang dikenakan bombon.

Sistem bombon adalah satu aktiviti yang memerlukan penglibatan dan kerjasama semua penduduk dalam menjayakan sistem tersebut. Setiap orang memainkan peranan masing-masing dari awal proses sistem tersebut. Setiap orang perlu memastikan tidak berlaku sebarang bentuk pencemaran atau pencerobohan berlaku di kawasan bombon. Setiap anggota pengamal bombon menjadi mata dan telinga yang cekap dengan melaporkan kepada ketua kampung sekiranya berlaku keadaan yang

\footnotetext{
${ }^{1}$ Maklumat diperoleh daripada Sami Bangun, 62 tahun melalui temu bual pada 14 Julai 2019.
} 
sedemikian. Semua anggota pengamal bombon bekerjasama menyumbang tenaga semasa aktiviti gotong royong membersihkan kawasan bombon dilakukan, begitu juga semasa aktiviti maganu bombon diadakan. Setiap orang berusaha untuk melakukan sesuatu mengikut kudrat dan kamhiran masing-masing. Bagi anggota yang tidak dapat hadir pada hari maganu bombon akibat kekangan kerja, uzur (tua) atau sakit dan kurang upaya, mereka tetap mempunyai peranan dengan memberi sumbangan dari segi kewangan untuk membantu pelaksanaan sistem bombon. Oleh sebab itu, semua anggota layak mendapat pembahagian ikan hasil tuaian bombon. Selepas semua proses pembahagian ikan selesai pada hari maganu bombon, kawasan persekitaran sungai akan dibersihkan, maka kawasan tersebut menjadi kawasan larangan semula dan sistem bombon diteruskan.

Sistem bombon adalah aktiviti tradisi masyarakat Kadazandusun yang telah diamalkan sejak zaman berzaman. Amalan ini berasas daripada kepercayaan tradisional masyarakat tersebut. Kepercayaan animisme yang dipegang oleh nenek moyang mereka menyebabkan mereka berusaha untuk mewujudkan hubungan yang baik dengan alam. Kepercayaan bahawa setiap unsur alam mempunyai semangat dan penunggu menjadikan mereka gerun dan menghormati alam. Amalan sistem bombon adalah antara aktiviti yang bersifat tempatan, menyeluruh dan bersepadu dengan alam. Oleh sebab itu, untuk memastikan tidak berlaku sebarang pelanggaran, sistem bombon dilaksanakan dengan adat.

Dalam kehidupan masyarakat Kadazandusun, adat bukan sahaja penting dalam pengurusan sumber alam tetapi juga dalam setiap proses kehidupan mereka. Adat merupakan satu sistem perundangan tradisional yang merangkumi satu set kepercayaan dan nilai-nilai yang mempengaruhi semua aspek kehidupan. Adat juga merupakan satu set peraturan dan prinsip yang tidak tertulis merangkumi seluruh kehidupan termasuk hubungan antara manusia dengan manusia dan antara manusia dengan dunia ghaib. Dalam pengurusan sumber alam, adat turut melibatkan banyak upacara yang bertujuan untuk pemuliharaan. Upacara-upacara yang diadakan bertujuan untuk mewujudkan hubungan yang baik dengan dunia semangat ghaib yang dipercayai mendiami alam ini (Segundad, 2004:181).

Amalan bombon pada asalnya dilaksanakan secara kecil-kecilan atau hanya melibatkan kawasan milik individu. Pemilik bombon menjaga kawasan bombon daripada diceroboh kerana dikhuatiri kawasan lubuk yang dalam mempunyai penunggu yang menyebabkan malapetaka. Kawasan lubuk yang dikenakan bombon adalah kawasan pembiakan ikan. Pemilik bombon hanya akan membuka bombon sesekali untuk penduduk bersama-sama mengambil ikan agar dapat dinikmati bersama. Sebelum kawasan bombon dibuka, ritual akan diadakan. Tujuan ritual diadakan adalah untuk menenangkan penunggu atau semangat di kawasan tersebut, agar tidak terkejut dan terganggu dengan kehadiran penduduk kampung. Ritual turut berfungsi untuk menjauhkan bala agar penduduk tidak ditimpa musibah semasa menangkap ikan pada waktu tersebut. Aktiviti menangkap ikan beramai-ramai dilakukan secara kerjasama agar dapat mengelakkan kemalangan berlaku. Selepas itu, kawasan tersebut akan dibombon semula. Penduduk tidak dibenarkan masuk ke kawasan tersebut tanpa izin. Hukuman dari segi adat akan dikenakan terhadap penceroboh. Hukum dari segi adat dikenakan sebagai pampasan kepada pemilik bombon dan untuk mengelakkan kemarahan penunggu atau semangat di kawasan yang dikenakan bombon.

Kini, amalan bombon diteruskan dengan kawasan bombon yang lebih besar dan penglibatan seluruh anggota komuniti. Bombon adalah milik bersama dan menjadi tanggung jawab semua anggota pengamal bombon. Amalan bombon mendidik masyarakat memelihara dan mengurus sumber perikanan sungai, berkongsi sumber alam dan mengambil mengikut keperluan sahaja. Melalui amalan bombon, mereka dapat menikmati ikan-ikan yang berkualiti dan bernilai secara berterusan. Amalan bombon juga membantu pemuliharaan kawasan persekitaran sungai dan menjaga kualiti air sungai. Pelanggaran peraturan bombon bermakna melanggar adat, mereka yang melanggar adat akan diadili oleh ketua kampung. Hukuman pelanggaran adat bombon adalah adalah sangat tinggi mengikut adat masyarakat Kadazandusun, iaitu seekor kerbau yang juga boleh dibayar dalam bentuk wang tunai sebanyak tiga ribu ringgit, nilai yang sama dengan harga seekor kerbau. Semua peralatan menangkap ikan juga akan dirampas.

Sistem bombon merupakan satu amalan tradisional yang berjaya menyumbang kepada pelestarian alam. Pelaksanaan sistem bombon dapat mengekalkan keseimbangan alam seterusnya memastikan 
penghasilan ikan yang berlipat ganda. Pada tahun 2001, pelaksanaan sistem bombon telah diiktiraf sebagai satu kaedah pemuliharaan ikan air tawar secara tradisional yang paling berkesan oleh pihak Jabatan Perikanan negeri Sabah (Wong et al, 2009). Sistem bombon telah diangkat sebagai satu sistem pengurusan pintar (smart partnership) antara pihak kerajaan dengan komuniti pengamal bombon. Melalui perkongsian pengurusan pintar tersebut, pihak kerajaan (melalui Jabatan Perikanan negeri Sabah) memberi bantuan dari segi teknikal, khidmat nasihat dan bantuan kewangan untuk mewujudkan pengurusan sistem bombon dengan lebih sistematik. Sistem bombon diperluas untuk membantu meningkatkan ekonomi anggota pengamal bombon dengan memperkenalkan beberapa aktiviti berbayar kepada pengunjung luar seperti aktiviti pancing dan lepas, spa (mandi) bersama ikan dan aktiviti berakit di kawasan sungai yang dikenakan bombon. Pengunjung yang datang juga berpeluang bermain dan memberi makanan kepada ikan di kawasan tersebut.

\section{Perubahan Sistem Nilai}

Suatu masa dahulu, sistem bombon adalah merupakan aktiviti yang dikaitkan dengan adat dan kepercayaan tradisional masyarakat Kadazandusun. pada hari ini, hampir semua masyarakat kadazandusun yang mendiami kawasan Kiulu, Tuaran sudah mempunyai pegangan agama baru seperti agama Kristian dan agama Islam. Perubahan nilai kepercayaan turut membawa perubahan nilai dalam amalan bombon. Jika dahulu amalan bombon adalah berasas kepada kepercayaan tradisional masyarakat tersebut, iaitu kepercayaan kepada kekuatan semangat ghaib yang mengawal bombon. Namun pada hari ini, tidak ada lagi ritual dijalankan mengiringi pelaksanaan bombon. Tradisi bombon telah disesuaikan dengan amalan dan kepercayaan agama yang baru dianuti oleh komuniti pengamal bombon itu sendiri. Kebanyakan penduduk di kawasan Kiulu sudah menerima pendidikan tinggi. Oleh itu, pengalaman dan pembelajaran akademik mereka juga telah membantu mengubah persepsi dan pemikiran masyarakat kepada pemikiran yang lebih logik dan rasional. Walau bagaimanapun, perubahan tersebut tidak mengurangkan nilai-nilai unggul yang terserlah melalui amalan bombon.

Nilai didefinisikan sebagai ukuran sikap dan kumpulan perasaan mengenai apa yang diinginkan atau yang tidak diharapkan, berkaitan apa yang boleh dilakukan dan sesuatu yang tabu untuk dilakukan (Abdul Syani (1995:3). Nilai juga boleh dikaitakn sebagai satu konsep budaya yang wujud dalam pemikiran manusia Wan Hashim Wan Teh (1998:xi). Konsep nilai boleh tercipta melalui interaksi antara ahli keluarga dan antara sesama anggota komuniti. Oleh itu, interaksi yang berlaku melalui satu aktiviti budaya seperti pelaksanaan sistem bombon, dapat mencerminkan nilai sosial komuniti pengamal bombon dengan tepat.

Melalui pelaksanaan sistem bombon, rasa hormat menghormati (popohimagon sopipantang-pantang) berjaya diserlahkan dalam kehidupan kalangan komuniti pengamal bombon. Hal ini adalah kerana sistem bombon era moden dapat dilaksanakan dengan jayanya apabila semua anggota pengamal bombon mempunyai rasa hormat menghormati dengan ketetapan yang telah diputuskan oleh majoriti anggota mereka. Sikap hormat menghormati dalam kalangan komuniti juga telah berjaya mengeratkan hubungan mereka melalui aktiviti yang dijalankan walaupun terdapat perbezaan pendapat pada peringkat awal pelaksanaan bombon. Walaupun pada hari ini masyarakat Kadazandusun di Kiulu, Tuaran, Sabah sudah mempunyai pegangan agama seperti agama Kristian dan agama Islam, namun mereka tetap menghormati adat dan kepercayaan tradisional nenek moyang mereka. Amalan sistem bombon menjamin komuniti setempat untuk mendapat sumber ikan air tawar secara berterusan dan menikmati aliran air sungai yang bersih.

Selain itu, pelaksanaan sistem bombon telah memupuk rasa takut (popohimagon kopondosian) untuk melakukan kesalahan dalam diri setiap individu. Suatu ketika dahulu, masyarakat takut untuk melakukan pelanggaran adat sistem bombon kerana gerun akan kemarahan kuasa ghaib yang dikaitkan dengan amalan sistem sistem. Masyarakat tradisional Kadazandusun percaya bahawa pelanggaran peraturan sistem bombon boleh menimbulkan bencana kepada seluruh komuniti mereka. Perubahan sistem kepercayaan dalam kalangan anggota komuniti pengamal bombon menyebabkan mereka tidak lagi dibayangi oleh perasaan takut akan semangat ghaib atau penunggu, tetapi lebih kepada rasa takut akan hukuman akibat pelanggaran tersebut. Individu yang didapati bersalah melanggar peraturan 
sistem bombon akan dikenakan penalti yang sangat besar dari segi adat dan boleh didakwa di mahkamah sivil dan dikenakan denda sehingga 50 ribu ringgit di bawah akta yang terkandung dalam Enakmen Perikanan Darat dan Akuakultur 2003, iaitu akta yang menyokong amalan sistem bombon pada hari ini.

Di samping rasa takut untuk melakukan kesalahan, pelaksanaan sistem bombon juga berjaya memupuk rasa malu (popohimagon obintingayaman) untuk melakukan kesalahan atau pelanggaran peraturan dan adat yang telah ditetapkan dalam komuniti. Tinggal dalam kelompok komuniti yang kecil menyebabkan setiap perkara yang berlaku dalam komuniti akan menjadi bahan bualan antara sesama mereka. Oleh itu, sebarang perlakuan atau perbuatan yang melanggar hukum apalagi yang berkaitan adat, perbuatan tersebut akan terus diperkatakan dan dijadikan panduan pada masa hadapan. Hal tersebut bukan sahaja menimbulkan rasa malu terhadap diri mereka sendiri, bahkan seluruh ahli keluarga pelaku juga akan terkena tempias akibat perbuatan tersebut. Akibat stigma tersebut begitu mendalam, ada penduduk kampung yang terpaksa membawa bersama seluruh ahli keluarga mereka berpindah ke tempat lain jika didapati bersalah melanggar adat bombon. Oleh sebab itu, masyarakat Kadazandusun seboleh mungkin berusaha untuk tidak melanggar adat kerana tidak mahu turut memberi malu kepada seluruh keluarga mereka. Rasa takut dan malu untuk melakukan pelanggaran hukum yang ditetapkan menunjukkan mereka menerapkan nilai mematuhi peraturan dan undangundang (tumanud do kooturan om undang-undang).

Pelaksanaan sistem bombon memang jelas memberi impak yang besar terhadap alam sekitar. Kepercayaan bahawa setiap unsur alam mempunyai semangat dan penunggu menyebabkan masyarakat tradisional Kadazandusun menjalankan banyak ritual semata-mata mahu mewujudkan hubungan yang baik dengan alam. Kepercayaan tradisional masyarakat tersebut sebenarnya membentuk mereka menjadi manusia yang menghormati dan menghargai alam semulajadi. Mereka percaya setiap objek semulajadi yang terdapat di sekitar mereka tersebut mempunyai rohnya sendiri dan amalan sistem bombon juga terhasil melalui kepercayaan tersebut. Namun begitu, pada hari ini masyarakat Kadazandusun menjadikan amalan sistem bombon sebagai platform yang dapat memupuk rasa cinta akan alam sekitar terutama dalam kalangan generasi baru. Masyarakat Kadazandusun tidak lagi dibayangi oleh kepercayaan terhadap kuasa-kuasa supernatural. Ilmu saintifik dan pemikiran logik memberi kesedaran kepada mereka bahawa perbuatan merosakkan alam sehingga menyebabkan pencemaran berlaku, akhirnya akan merugikan mereka sendiri. Warisan budaya bombon melahirkan rasa cinta akan sekitar dapat diterapkan dalam diri setiap individu sejak kecil melalui penglibatan mereka dalam setiap aktiviti yang berkaitan dengan sistem bombon sekaligus dapat menerapkan nilai menyayangi dan menghargai alam sekitar.

Pelaksanaan sistem bombon adalah antara aktiviti sosial masyarakat Kadazandusun yang berjaya memupuk semangat kebersamaan (popohimagon pisaan) yang tinggi dalam kalangan ahli komuniti. Sistem bombon dianggap sebagai milik bersama seluruh anggota komuniti. Oleh itu, semua anggota komuniti berusaha untuk hadir dan melibatkan diri dalam setiap aktiviti berkaitan sistem bombon. Hasil tuaian ikan dikongsi bersama dengan semua anggota komuniti bagi membolehkan golongan tua dan kurang upaya turut menikmati hasil sumber alam mereka. Aktiviti maganu bombon boleh dijadikan contoh terbaik yang menunjukkan perpaduan dan semangat kebersamaan yang jitu. Penglibatan seluruh ahli komuniti pengamal bombon dapat dilihat pada hari bombon dibuka untuk aktiviti tersebut. Mereka bergotong royong melaksanakan setiap tugasan yang diberi agar proses maganu bombon sehingga aktiviti pembersihan kawasan dapat dijalankan dengan lancar. Anggota komuniti turut mengambil kesempatan untuk berkumpul beramai-ramai dan meraikan hasil tangkapan ikan dengan gembira dengan penuh kesyukuran. Semangat kebersamaan yang ditunjukkan melalui pelaksanaan sistem bombon menunjukkan komuniti tersebut mengamalkan nilai saling membantu dan bekerjasama (miuhup om mogisosokodung).

Amalan sistem bombon pada hari ini tidak lagi dibayangi oleh sistem kepercayaan tradisional nenek moyang masyarakat Kadazandusun. Komuniti pengamal bombon tidak lagi menjalankan ritual atau persembahan untuk semangat ghaib dan penunggu sungai. Pelaksanaan sistem bombon pada hari ini lebih menyerlahkan nilai-nilai murni yang bersifat universal berkaitan dengan pelestarian alam semula jadi dan hubungan antara sesama manusia. 
Amalan sistem bombon layak diangkat sebagai warisan kebangsaan selari dengan Akta Warisan Kebangsaan 2005 (Akta 645) yang menggariskan klasifikasi konsep warisan kebudayaan tidak ketara sebagai kegiatan budaya yang dilakukan oleh manusia termasuklah tradisi lisan, amalan sosial, ritual, perayaan tradisi serta ilmu pengetahuan dan amalan yang berkaitan dengan alam. Sistem bombon merupakan aktiviti amalan budaya masyarakat Kadazandusun sejak zaman nenek moyang mereka sehingga berjaya membina kearifan tempatan yang mempunyai signifikan dalam kelangsungan hidup masyarakat tersebut. Sebagai amalan budaya turun temurun, sistem bombon telah memenuhi fungsi kearifan tempatan seperti yang digariskan oleh Rohana Sufia, Sumarni dan Amirudin (2016) iaitu, sistem bombon telah menjadi amalan yang berjaya menjadi identiti masyarakat Kadazandusun. Selain itu, amalan sistem bombon juga telah diterima sebagai agen penyatuan seluruh anggota komuniti tanpa mengira amalan kepercayaan mereka pada hari ini. Malahan melalui pelaksanaan sistem bombon juga, kearifan tempatan tersebut telah menjadi wadah dalam mewujudkan keharmonian dalam sebuah komuniti.

\section{Kesimpulan}

Sistem bombon dilaksanakan untuk mewujudkan hubungan yang baik antara manusia dengan dunia ghaib seterusnya untuk mengatasi masalah kekurangan sumber ikan air tawar dan mengelakkan pencemaran berlaku ke atas sungai. Aktiviti yang berasas kepada kepercayaan tradisional masyarakat tersebut berjaya melalui sejarah yang panjang dan mampu bertahan sehingga hari ini. Pelbagai inovasi dan penambahbaikan dilakukan untuk menjadikan aktiviti yang berkaitan dengan sistem bombon turut dapat menyumbang kepada persekitaran sosial, terutama dari segi pembangunan sosio-ekonomi masyarakat Kadazandusun. Perubahan yang paling ketara adalah perubahan dari segi nilai kepercayaan yang melatari pelaksanaan sistem tersebut. Namun yang pasti, amalan tradisional ini berjaya menyatupadukan seluruh anggota komuniti pengamal sistem tersebut. Amalan sistem bombon juga berjaya membentuk sikap-sikap yang baik dalam kalangan komuniti pengamalnya. Banyak nilai murni yang diamalkan oleh komuniti tersebut terserlah melalui pelaksanaan aktiviti budaya tersebut.

\section{Rujukan}

Abdul Mukti. (2010). Beberapa kearifan lokal suku Dayak dalam pengelolaan sumber daya alam. Malang: Universitas Brawijaya.

Abdul Syani. (1995). Sosiologi dan perubahan budaya. Indonesia: Pustaka Jaya.

Adlina Ab. Halim, Sri Rahayu Ismail, N. Othman, \& Jayum Jawan. (2012). Indigenous knowledge and biodiversity conservation in Sabah, Malaysia. International Journal of Social Science and Humanity, 2(2), 159-163. doi: 10.7763/IJSSH.2012.V2.88

Akta Warisan Kebangsaan. Cetakan semula. Undang-undang Malaysia. Akta 645 (2005).

Atmadi, G. (2013). The implementation of corporate communication based on local wisdom in facing globalization. In Prosiding The 5th International Conference on Indonesian Studies: "Ethnicity and Globalization" (pp. 189-204).

Ayatrohaedi. (1986). Kepribadian budaya bangsa: Local Genius. Jakarta: Dunia Pustaka Jaya.

Er, A. C., Sivapalan Selvadurai, Lyndon, N., Chong, S. T., Adam, J. H., Mohd Fuad Mat Jali., Hamzah Jusoh. (2012). The evolvement of tagal on ecotourism and environmental conservation: A case study in Kampong Luanti Baru, Sabah. Advances in Natural and Applied Sciences, 6(1), 61-64.

Evans, E. E. (1987). Teori agama primitif. Bangi: Penerbit Universiti Kebangsaan Malaysia.

Evans, I. H. N. (1917). "Orang Dusun” of British North Borneo. Journal of Royal Anthropological Institute of Great Britain and Ireland, 47, 151-159.

Evans, I. H. N. (1923). Studies in religion, folk-lore and custom in British North Borneo and the Malay Peninsula. Cambridge: Cambridge University Press.

Evelina L. W. (2016). Vertical communication based on local wisdom: A study of world class university. Pertanika Journal Social Sciences \& Humanities, 24, 59-70. 
Foo, J. \& Harifah Mohd Noor. (2012). Respon masyarakat tempatan terhadap pelaksanaan sistem Tagal. Malaysia Journal of Society and Space, 8(2), 30-37.

Foo, J. (2011). Sistem Tagal dalam industri pelancongan: Manfaat kepada komuniti. Malaysia Journal of Society and Space, 7(1), 14-25.

Foo, J. (2019). Pemuliharaan warisan kebudayaan melalui sistem tagal sungai di Sabah. Dlm. Ismail Ibrahim, Mat Zin Mat Kib \& Sim, C. C. (Pnyt.). Borneo dalam kepelbagaian perspektif (159174). Kota Kinabalu: Universiti Malaysia Sabah.

H. Iin Wariin Basyari. (2014). Nilai-nilai kearifan lokal (Local wisdom) tradisi memitu pada masyarakat Cirebon (Studi masyarakat desa Setupatok Kecamatan Mundu). Edunomic Jurnal, $2(1), 47-56$.

Halim, A. Ab., Othman, N., Ismail, S. R., Jawan, J. A., \& Ibrahim, N. N. (2012). Indigenous knowledge and biodiversity conservation in Sabah, Malaysia. International Journal of Social Science and Humanity, 2(2), 159-163.

Haminuddin Udin. (1991). Masyarakat Kadazandusun di daerah Ranau: Kajian identiti dan interaksi antara agama. Kuala Lumpur: Universiti Malaya.

Kamus Dwibahasa Melayu - Inggeris Dewan. (2012). Kuala Lumpur: Dewan Bahasa dan Pustaka.

Kulip, J. (2016). A study on the traditional beliefs and practices on the agricultural land, forest resources and conservation by the Dusun people in Tambunan district, Sabah, Malaysia. Congress Traditional Knowledge for Ecosystem Services \& Asian Countries-Folk Culture: Proverbs, Old Sayings and Community Rules. 2-4 March. Kuala Lumpur, Malaysia.

Luping, H. J. (2009b). Indigenous ethnic communities of Sabah, the KadazanDusun. Kuala Lumpur: Kementerian Maklumat, Komunikasi, dan Kebudayaan Malaysia.

Minah Sintiam. (2013). Kepercayaan dan amalan Kadazandusun dalam pemeliharaan alam sekitar. Diperoleh pada 2 Februari 2018 daripada www.researchgate.net/publication/272357429

Mungmachon, R. (2012). Knowledge and local wisdom: Community treasure. International Journal of Humanities and Social Science, 2(13), 174-181.

Orne, J. \& Bell, M. M. (2015). An invitation to qualitative fieldwork. New York: Routledge.

Rohana Sufia, Sumarmi, \& Ach. Amirudin. (2016). Kearifan lokal dalam melestarikan lingkungan hidup (Studi kasus masyarakat adat desa kemiren kecamatan glagah kabupaten banyuwangi). Jurnal Pendidikan, 1(4), 726-731.

Segundad, P. (2004). Biodiversity and tradition in Malaysia. Dlm. R. S. Gottlieb (Pnyt.). This sacred Earth: Religion, nature, environment (180-185). Great Britain: Routledge.

Shim, P. S. (2007). Inland people of Sabah before, during and after Nunuk Ragang. Sabah: Borneo Cultural Heritage Publisher.

Tangil, J., \& Amat, A. (2018). Fungsi hukum adat dalam kejayaan sistem Tagal di Kiulu, Tuaran, Sabah. Kertas kerja dibentangkan di Prosiding Persidangan Antarabangsa Sains Sosial dan Kemanusiaan ke-7 anjuran Universiti Kebangsaan Malaysia pada 12-15 November.

Tangil, J., \& Amat, A. (2020). Local wisdom in the Bombon System by the Kadazandusun society in Kiulu, Tuaran, Sabah. Malaysian Journal of Social Sciences and Humanities (MJSSH), 5(2), 77 86.

Tombung, R.B. (1994). Sastera Dusun. Kota Kinabalu: Persatuan Dusun Sabah Bersatu.

Tongkul, F. (2007). Traditional system of indigenous peoples of Sabah, Malaysia (ed. ke-2). Kota Kinabalu: Pacos Trust.

Tongkul, F., Lasimbang, A., Lasimbang C., \& Chin, Jr. P. (2013). Traditional knowledge and SFM experience from Malaysia. Unasylva, 64, 41-49.

Wan Hashim Wan Teh \& Ismail Hamid (Pnyt.). (1998). Nilai budaya masyarakat desa: Kajian etnografi di Wang Kelian, Perlis. Kuala Lumpur: Dewan Bahasa dan Pustaka

Williams, T. R. (1965). The Dusun: A North Borneo society. New York: John Wiley \& Sons.

Williams, T. R. (1969). A Borneo childhood enculturation in Dusun society. New York: Holt, Rinehart and Winston Inc.

Wong, J. Z., Etoh, S., \& Sujang, A. B. (2009). Toward sustainable community based fishery resources management: The Tagal system of Sabah, Malaysia. Southeast Asian Fisheries Development Center, 7(2), 18-23.

Zeno Fernandez. (2009). Budaya tagal di Tamparuli. Kota Kinabalu: Universiti Malaysia Sabah 